\title{
O.JS

\section{O PAPEL DO TCC NA FORMAÇÃO DO PROFESSOR PESQUISADOR: O CASO DA LICENCIATURA EM GEOGRAFIA DO IFRN}

\author{
João Correia Saraiva Junior ${ }^{1}$
}

${ }^{1}$ Professor pelo Instituto Federal de Educação, Ciência e Tecnologia do Rio Grande do Norte. Mestre em Geografia pela Universidade Federal do Ceará (UFC). E-mail: joao.correia@ifrn.edu.br - ORCID: http://orcid.org/0000-0001-9100-1241

Artigo recebido em 18/02/2021 e aceito em 28/02/2021

\begin{abstract}
RESUMO
A etapa de produção do Trabalho de Conclusão de Curso (TCC) é marcada por diversos desafios que exercem um importante papel na criação e/ou desenvolvimento de pesquisadores. Nos cursos de licenciatura, desenvolver uma pesquisa na forma de TCC é uma tarefa que se coloca diante dos desafios da formação de professores-pesquisadores. Tendo isso em vista, o objetivo geral deste artigo é discorrer sobre o papel do Trabalho de Conclusão de Curso na formação de futuros profissionais da educação geográfica, tendo como estudo de caso o curso de Licenciatura em Geografia do IFRN. A metodologia é baseada em revisão conceitual, aplicação de questionários e síntese dos dados coletados. Tendo os dados sido analisados, os resultados apontam que, na Licenciatura em Geografia do IFRN, os impactos da produção do TCC têm sido positivos na formação de professores-pesquisadores, embora existam entraves que necessitam da atenção, principalmente, do corpo docente na geração de um ambiente propício à construção do conhecimento de maneira colaborativa.
\end{abstract}

Palavras-chave: Formação docente. Ciência geográfica. Componente curricular. Ambiente tóxico. Ambiente colaborativo.

\section{THE ROLE OF THE TCC IN THE TRAINING OF THE RESEARCH- TEACHER: THE CASE OF THE LICENSE GRADUATION IN GEOGRAPHY OF THE IFRN}

\begin{abstract}
The production stage of the Graduation Conclusion Paper (TCC) is highlighted by several challenges that play an important role in the creation and / or development of researchers. In undergraduate license courses, developing research in the form of TCC is a task that faces the challenges of research-teacher training. The general objective of this article is to discuss the role of the Graduation Conclusion Paper in the training of future professionals in geographic education, having as a case study the IFRN Graduation license in Geography. The methodology is based on conceptual review, application of questionnaires and synthesis of the collected data. Having analyzed the data, the results indicate that, in the IFRN Graduation license in Geography, the impacts of the TCC production have been positive in the training of researchteachers, although there are obstacles that need attention, mainly, of the teaching staff in the generation an environment conducive to the construction of knowledge in a collaborative way.
\end{abstract}

Keywords: Teacher training. Geographic science. Curricular component. Toxic environment. Collaborative environment.

Saraiva Junior, 2021

ISSN 2594-9616 92

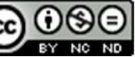

This work is licensed under a Creative Commons Attribution-NonCommercial-NoDerivatives 4.0 International License 


\title{
EL PAPEL DEL TCC EN LA FORMACIÓN DEL PROFESOR INVESTIGADOR: EL CASO DEL PREGRADO EN GEOGRAFÍA DEL IFRN
}

\begin{abstract}
RESUMEN
La fase de producción del Trabajo de Conclusión de Grado (TCC) es marcada por varios desafíos que juegan un papel importante en la creación y/o desarrollo de investigadores. En los cursos de pregrado, desarrollar una investigación en forma de TCC es una tarea que se pone ante de los desafíos de la formación de profesores-investigadores. Teniendo esto en cuenta, el objetivo general de este artículo es discutir acerca del papel del Trabajo de Conclusión de Grado en la formación de los futuros profesionales de la enseñanza geográfica, teniendo como estudio de caso la carrera del grado en Geografía del IFRN. La metodología se basa en la revisión conceptual, la aplicación de cuestionarios y la síntesis de los datos colectados. Analizados los datos, los resultados indican que, en el Pregado en Geografía del IFRN, los impactos de la producción de TCC han sido positivos en la formación de profesores-investigadores, aunque existen obstáculos que requieren la atención, principalmente, del profesorado en la generación de un entorno propicio para la construcción del conocimiento de forma colaborativa.
\end{abstract}

Palabras-claves: Formación docente. Ciencia geográfica. Componente curricular. Ambiente tóxico. Ambiente colaborativo.

\section{INTRODUÇÃO}

A construção do fazer científico deve ser estimulada constantemente por docentes em seus próprios afazeres pedagógicos cotidianos, por meio da produção do conhecimento sob diversas perspectivas e diferentes estratégias desenvolvidas em sala de aula e nos demais espaços do ambiente escolar.

Dito isso, a necessária renovação da ciência passa, necessariamente, pela atividade docente, pois estes são os principais atores responsáveis pela articulação entre os saberes locais e as bases científicas do sistema educacional. ou seja, tarefas como planejamento de aula, aplicação de metodologias e avaliação discente exigem muito empenho das Instituições de Ensino Superior (IES).

Todavia, o que ocorre é que, nesses espaços acadêmicos, nem sempre há um ambiente colaborativo que favoreça uma capacitação adaptada aos anseios e demandas sociais. Em vez disso, encontra-se, por vezes, um contexto de meritocracia, vaidade acadêmica, assédio moral e competividade estéril, conforme apontam Sanchez e Inanarelli (2012), Paixão et al., (2014), Pinheiro Machado (2016), Nobre (2016) e Cordula e Nascimento (2018). Em vista disso, para além dos problemas das relações interpessoais, é preciso destacar o ensino e a aprendizagem do fazer científico, e, principalmente, o que diz respeito à maneira como ocorre essa relação. 
No Instituto Federal de Educação, Ciência e Tecnologia do Rio Grande do Norte (IFRN), a produção científica é estimulada em diversos níveis de ensino, desde a Educação Básica à PósGraduação. Em todos os níveis, destaca-se o estímulo à produção científica, em particular, nos cursos de licenciatura, que são, por excelência, lócus de formação dos profissionais que irão atuar em todas as áreas do conhecimento, o que faz desses cursos, portanto, centros propagadores da ciência e tecnologia.

O curso de Licenciatura em Geografia do Campus Natal Central (LIGIFRN) foi fundado em 2003, com registros de primeiros egressos em 2006. Desde então, o curso de LIGIFRN, a partir de um currículo que busca unir ensino, pesquisa e extensão (IFRN,2012), vem formando professores de Geografia para atuar na Educação Básica. Nesse sentido, o fazer científico é realizado permanentemente durante os 8 períodos exigidos, em particular, durante a realização do Estágio Supervisionado e do Trabalho de Conclusão de Curso, que se constituem como etapas importantes na construção de professores-pesquisadores.

No entanto, cabe indagar: em um curso de licenciatura, a produção do relatório de estágio supervisionado não seria suficiente para formar professores? Qual a importância da elaboração de um TCC no curso de Licenciatura em Geografia? Os temas não deveriam ser voltados apenas para o ensino-aprendizagem em Geografia? Quais as dificuldades enfrentadas pelos alunos para concluírem o TCC?

Partindo desses questionamentos, o objetivo geral deste artigo é discorrer sobre o papel do Trabalho de Conclusão de Curso na formação de professores-pesquisadores no curso de Licenciatura em Geografia do IFRN. Os objetivos específicos buscam, em relação ao caso específico do curso de Licenciatura em Geografia do IFRN, caracterizar o processo formativo de professores, compreender as etapas de construção do Trabalho de Conclusão de Curso, e identificar os aspectos positivos e negativos da exigência do Trabalho de Conclusão de Curso.

Em relação à metodologia, essa é uma pesquisa de cunho exploratório com elementos de estudo de caso. Desse modo, os percursos metodológicos foram executados por meio de revisão da literatura, aplicação de questionários e tabulação dos dados. Quanto às expectativas, espera-se que este trabalho possa contribuir com as reflexões acerca do TCC como elemento importante na formação de professores-pesquisadores. 


\section{MATERIAIS E MÉTODOS}

A revisão de literatura acerca da perspectiva da formação de professores-pesquisadores foi realizada em artigos, dissertações e teses. Além disso, foram analisados os documentos oficiais do IFRN que tratam do processo formativo, como também os principais dispositivos de orientação da instituição, como a Organização Didática do IFRN e o Plano Pedagógico do Curso de Licenciatura em Geografia do IFRN.

Foi realizado um levantamento de dados de forma on-line, através de questionários disponibilizados por meio do Google Forms, ferramenta que, após a aplicação, gerou uma planilha síntese das respostas que foram analisadas nos resultados A aplicação de questionários ocorreu de maneira virtual, a partir da efetivação de contatos, por meio de redes sociais (Facebook, Instagram, Whatsaap e e-mail), com ex-alunos que concluíram o curso (independente do ano de conclusão). No formulário (Quadro 01) não foram solicitadas informações como nome do participante, e-mail ou mesmo telefone para não comprometer o envio das respostas pelos respondentes e para o sigilo ser contemplado.

QUADRO 01 - FORMULÁRIO DISPONIBILIZADO AOS PARTICIPANTES DA PESQUISA TCC da Licenciatura em Geografia do IFRN

Atenção! Por gentileza, só responda se você concluiu o curso de Licenciatura em Geografia no IFRN! Caro(a) participante, inicialmente muito obrigado pela disponibilidade! Segundo: esse formulário é para obtenção de dados sobre a concepção dos profissionais formados na Licenciatura em Geografia do IFRN acerca da produção do Trabalho de Conclusão de Curso (TCC). Os dados servirão de base para melhorias na formação de professores e na educação superior pública.

Qual o ano de conclusão do curso?

Você apresentou dificuldades na produção do Projeto de Pesquisa? Em caso positivo, quais foram essas dificuldades? Podem ser aspectos da formação no IFRN e questões ligadas à família, ao trabalho, aos recursos financeiros, entre outros

As contribuições dos avaliadores do Projeto de Pesquisa foram importantes para a melhoria do seu Projeto de Pesquisa?

Sim Não

A existência de um(a) docente responsável pelo acompanhamento da produção do Projeto de Pesquisa e do TCC contribuiu na finalização do seu TCC?

Sim Não

O processo de orientação do TCC foi satisfatório?

Sim Não

Você apresentou dificuldades na produção do TCC? Em caso positivo, quais foram essas dificuldades? Podem ser aspectos da formação no IFRN e questões ligadas à família, ao trabalho, aos recursos financeiros, entre outros.

Qual o papel que a produção do TCC exerceu em sua formação como professor(a)? 


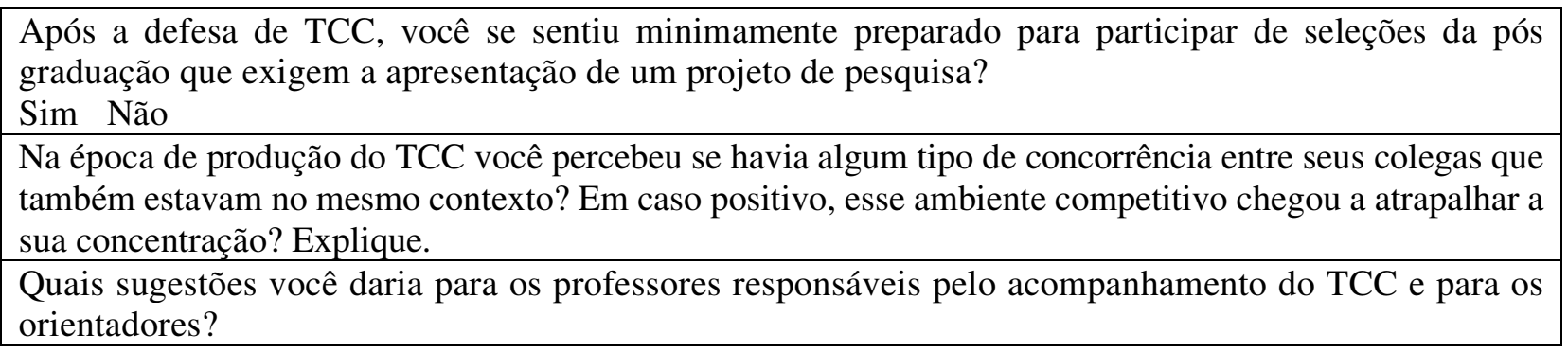

Fonte: Adaptado dos trabalhos de Guedes e Guedes (2012)

Após o período de coleta, foi gerada uma planilha com as respostas dos participantes e feita a tabulação dos dados para a interpretação.

\section{REFERENCIAL CONCEITUAL}

\section{O processo formativo do professor de Geografia no IFRN}

A compreensão da importância de se formar professores- pesquisadores vêm ganhando espaço no sistema educacional brasileiro. Isso vem acontecendo de tal forma que foi subsidiada a expansão dos programas de pós-graduação voltados para a educação, em diversos departamentos, e a expansão da Educação à Distância no processo de interiorização do sistema educacional brasileiro.

Como forma de melhorar a acessibilidade das licenciaturas, os Centros Federais de Educação Tecnológica (CEFET) do Brasil passaram a ofertar cursos de formação docente, particularmente nas áreas de Matemática e Física, no primeiro decênio do ano 2000. No Rio Grande do Norte, o CEFETRN passou a ofertar a Licenciatura em Geografia a partir de 2003.

Em 2008, como forma de transformar o centro em uma instituição de ensino completa o CEFET-RN torna-se IFRN e, como isso, passa a ter como função social uma formação humana integral (IFRN, 2012).

Nesse sentido, devendo as diretrizes do curso de Licenciatura em Geografia estar alinhadas à função social do IFRN, o Plano Pedagógico do Curso afirma que ele "tem como objetivo geral formar o profissional docente com um saber plural, constituído pela internalização de saberes da área específica, saberes pedagógicos e saberes experienciais”. (IFRN, 2018, p.09)

Em relação aos objetivos específicos, dentre os vários, destacam-se 
-Habilitar o Licenciado em Geografia para atuação nos níveis Fundamental e Médio da Educação Básica, integrando-se às novas diretrizes indicadas ao Ensino; -Formar profissionais devidamente habilitados em atuar no ensino, pesquisa e extensão, sem dissociar as referidas habilidades;

-Proporcionar uma formação teórica e prática possibilitando um efetivo exercício do seu conhecimento diante dos desafios enfrentados;

-Desenvolver postura investigativa de modo tal que problematize a realidade educacional (IFRN, 2018, p.10);

Esses objetivos são difíceis de alcançar quando se leva em conta que a formação dos professores de Geografia possui múltiplos desafios, os quais são impostos de acordo com as demandas sociais, e, por isso, mudam ao sabor do contexto histórico. Uso de tecnologias, maior articulação entre as escalas geográficas (cada vez mais intensa em função da globalização), poucos recursos financeiros e dificuldades de se estabelecer uma formação continuada são apenas algumas das situações que se colocam a serem constantemente avaliadas pelas instituições formadoras.

Situações que, em um primeiro plano, estão a serviço do seguinte questionamento: O que seria um bom professor de Geografia? Procurando responder essa questão, segundo Sousa Neto (2003), uma boa aula de Geografia responde a perguntas como o que, porque, como e onde ocorrem os fenômenos geográficos. Nesse sentido, um professor deve ser preparado para ter condições de analisar a realidade a partir da aplicação de conceitos científicos.

$\mathrm{Na}$ formação inicial ou continuada é que a concepção pedagógica desse professor dá saltos qualitativos, pois, segundo Menezes e Kaercher (2015), desde a Educação Básica, a figura do professor na vida do indivíduo começa a exercer forte influência, particularmente quando se trata das atitudes tomadas em sala de aula. Ainda segundo Menezes e Kaercher (2015), há necessidade constante de renovação dos paradigmas que são ensinados nas Instituições de Ensino Superior (IES), pois, muitas vezes, a formação dos professores apresenta alto distanciamento da realidade escolar.

Em vista disso, a formação na Licenciatura deve contribuir para a desconstrução de práticas escolares conservacionistas e autoritárias que insistem em permanecer no sistema educacional. Não só isso, a formação em Licenciatura deve ajudar os futuros professores a superar os desafios que se impõem a cada ano, articulando cientificidade e afetividade na construção de sua própria autonomia.

Dessa forma, não basta apenas saber o conteúdo, o professor de Geografia precisa ter clareza da sua profissão; saber articular os conhecimentos pedagógicos e as teorias da aprendizagem dos alunos, com um olhar integrado sobre a realidade educacional deles (MENEZES e KAERCHER, 2015; BATISTA et al., 2019); e ainda proporcionar uma formação cidadã ao corpo discente 
(CAVALCANTI e SOUZA, 2014). Todos esses aspectos precisam estar inclusos na formação dos professores de Geografia.

Cavalcanti (2017) defende que uma boa preparação docente em Geografia é aquela que não valoriza apenas os conteúdos da Geografia acadêmica, mas estimula uma reflexão constante sobre seu significado na atuação docente. É fundamental que a formação de professores de Geografia tenha como pilar principal estimular os alunos a pensarem sobre a realidade a partir da dimensão espacial, com seus atributos e suas relações, a fim de que sejam capazes de responder a perguntas como o que é o mundo e qual o lugar deste sujeito no mundo.

Tal formação ampla de futuros docentes repousa na indissociabilidade entre ensino, pesquisa e extensão. É importante estimular de maneira constante o reconhecimento dos saberes e sua socialização (VEIGA, 2005).

Educar por meio da pesquisa (DEMO, 2000) é fundamental para a construção da identidade de professores, que não irão apenas apresentar idéias de pesquisadores, mas que poderão perceber-se como sujeitos capazes de articular os saberes locais e as bases científicas. Por isso, a investigação científica deve fazer parte da formação do professor de Geografia (MENEZES e KAERCHER, 2015)

Partindo de tais premissas sobre a formação docente, o currículo do curso de LIGIFRN está organizado em oito semestres, que somam um total de 3.200 horas distribuídas em diversas atividades. As bases da ciência geográfica são contempladas nas diversas disciplinas, como, por exemplo, Geografia Cultural, Climatologia, Geomorfologia e Geografia Urbana. Quanto ao eixo didático-pedagógico, existem disciplinas como Didática, Metodologia do Ensino de Geografia, e Mídias Educacionais.

Ao longo do curso, os graduandos têm diversas oportunidades de entrarem em contato com a pesquisa em ensino-aprendizagem em Geografia, como pode ser observado nos exemplos demonstrados a seguir, no Quadro 2: 
QUADRO 2: ATIVIDADES OBRIGATÓRIAS DESENVOLVIDAS NA LICENCIATURA EM GEOGRAFIA DO IFRN

\begin{tabular}{|c|c|}
\hline Tipologia & Caracte rísticas \\
\hline $\begin{array}{c}\text { Seminários de Orientação ao Desenvolvimento de Práticas } \\
\text { Educativas e Formação Docente }\end{array}$ & $\begin{array}{c}\text { Articulação entre teoria e prática na atuação docente do licenciando e que } \\
\text { valoriza as posturas interdisciplinares, e que considera o princípio da } \\
\text { indissociabilidade entre ensino, pesquisa e extensão. }\end{array}$ \\
\hline $\begin{array}{c}\text { Seminário de Orientação ao Estágio Supervisionado (Estágio } \\
\text { Docente) }\end{array}$ & $\begin{array}{c}\text { Realização de estágio em escolas da rede pública como forma de prática } \\
\text { pedagógica que possibilita a observação e reflexões acerca do cotidiano } \\
\text { escolar e ensino de Geografia }\end{array}$ \\
\hline Atividades Teórico-Práticas de Aprofundamento (ATPA) & $\begin{array}{c}\text { Participação em eventos, Participação em grupos de pesquisa, Participação } \\
\text { em cursos de formação }\end{array}$ \\
\hline Atividades desenvolvidas nas disciplinas & Planos de aula, Artigos, Seminários, Relatórios de campo, resenhas, \\
resumos.
\end{tabular}

Fonte: Adaptado de IFRN (2018).

Além dessas, há, previstas no PPC, atividades tidas como complementares à formação do licenciando, caso surja a oportunidade de ele cursá-las. Essas atividades complementares encontramse indicadas no Quadro X a seguir:

QUADRO 3: ATIVIDADES DE FORMAÇÃO COMPLEMENTAR QUE PODEM SER DESENVOLVIDAS DURANTE A GRADUAÇÃO NA LICENCIATURA EM GEOGRAFIA DO IFRN.

\begin{tabular}{|c|c|}
\hline Tipologia & Caracte rísticas \\
\hline Iniciação Científica & $\begin{array}{c}\text { Possibilidade de participação por meio de aprovação em editais lançados } \\
\text { anualmente com oferta de bolsas ou na modalidade voluntária. }\end{array}$ \\
\hline Atividades de Extensão & $\begin{array}{c}\text { Possibilidade de participação por meio de aprovação em editais lançados } \\
\text { anualmente com oferta de bolsas ou na modalidade voluntária. }\end{array}$ \\
\hline Monitoria & $\begin{array}{c}\text { Possibilidade de participação por meio de aprovação de plano de trabalho por } \\
\text { um(a) docente. }\end{array}$ \\
\hline Residência Pedagógica & $\begin{array}{c}\text { Atividades como regência de sala de aula e intervenção pedagógica orientadas } \\
\text { por um profissional da escola e da instituição formadora. }\end{array}$ \\
\hline $\begin{array}{c}\text { Programa Institucional de Bolsas de } \\
\text { Iniciação à Docência (PIBID) }\end{array}$ & $\begin{array}{c}\text { Antecipação do vínculo entre futuros professores e as salas de aula da rede } \\
\text { pública de ensino }\end{array}$ \\
\hline
\end{tabular}

Fonte: Adaptado de IFRN (2018).

As oportunidades de entrar em contato com a pesquisa em ensino-aprendizagem, a partir de disciplinas e de atividades curriculares ou complementares iniciam-se, geralmente, já no segundo período. Diante disso, é a partir desse momento no curso que o discente tem chances de desenvolver habilidades e competências pedagógicas a serem aplicadas em sala de aula por meio da prática dos componentes curriculares.

Quanto ao Trabalho de Conclusão de Curso, ele corresponde a "uma produção acadêmica que expressa as competências e as habilidades desenvolvidas ou os conhecimentos adquiridos pelos estudantes durante o curso" (IFRN, 2012, p. 72). Na LIGIFRN, a monografia é o formato adotado como tipo de TCC (IFRN, 2018). Na feitura do TCC, o licenciando surge como protagonista na 
produção de saberes, consagrando a tão debatida figura do professor-pesquisador como uma das principais do sistema educacional.

O desenvolvimento de um TCC, ainda que não seja na área de ensino de Geografia, não compromete a formação de professores pesquisadores, pelo contrário: a formação docente parece ser reforçada ao ampliar o leque de possibilidades dos licenciandos entrarem em contato com o universo da pesquisa sobre o ensino de Geografia.

\section{Etapas da construção do trabalho de conclusão de curso no curso de licenciatura em Geografia do IFRN}

A elaboração do TCC inicia-se apenas durante o $7^{\circ}$ período e encerra-se no $8^{\circ}$. No entanto, todas as disciplinas ofertadas no curso e atividades complementares, desde o $1^{\circ}$ período, contribuem no processo de construção do pensamento científico do discente, possibilitando o acesso a diferentes linhas de pesquisa da ciência geográfica, referenciais teóricos e metodologias diversificadas.

Entre essas disciplinas, podem ser citadas algumas como Leitura e Escrita de Textos Acadêmicos e de Divulgação Científica, Teoria e Método da Geografia, Epistemologia da Ciência, e Metodologia do Trabalho Científico. Essas disciplinas oferecem maior suporte para a produção do TCC por tratarem de conteúdos que atendem a todas as linhas de pesquisa, e por possibilitarem maior reflexão sobre a escrita científica.

Segundo o Plano de Curso da Licenciatura em Geografia do IFRN (LIGIFRN), o Desenvolvimento da Pesquisa Acadêmico-Científica é um componente curricular obrigatório equivalente ao Trabalho de Conclusão de Curso, que soma uma carga horária de 120h, distribuídas entre o $7^{\circ}$ e $8^{\circ}$ períodos (IFRN, 2018).

A produção do Projeto de TCC da LIGIFRN ocorre geralmente no $7^{\circ}$ período, sob os cuidados de um(a) docente responsável pela disciplina do projeto, por meio de uma etapa de formalização junto ao docente responsável pela orientação do TCC e registrado pela coordenação de curso durante o Seminário de Orientação ao Desenvolvimento de Pesquisa Acadêmico Científicas I. Os estudantes têm total liberdade de produzirem pesquisas relacionadas às áreas de Geografia Escolar, Geografia Física e Geografia Humana.

É costume acontecer, ao final do $7^{\circ}$ período, um procedimento que é denominado de “Qualificação do Projeto de TCC”, em que há a apresentação da proposta de pesquisa que deverá ser 
avaliada pelo(a) orientador(a), um(a) convidado(a) e pelo(a) docente responsável pelo TCC. Nesse momento, são feitas sugestões de alterações, quando necessárias, e preparação para a etapa de produção do TCC.

No $8^{\circ}$ período, é realizada a etapa de produção do TCC durante a realização do Seminário de Orientação ao Desenvolvimento de Pesquisa Acadêmico-Científica II. Nesse momento, a figura do(a) orientador(a)se torna ainda mais presente por meio das atividades previstas no Plano de Curso, como execução do cronograma; reuniões periódicas entre o orientando e o professor orientador; redação do TCC pelo discente; e "avaliação e defesa pública perante uma banca examinadora” (IFRN, 2018, p. 30).

É importante destacar que o Plano de Curso da LIGIRFN sofreu atualizações em 2006, 2012 e 2018, com mudanças de carga horária, componentes curriculares e estabelecimento de normas sobre os procedimentos pedagógicos. Essas alterações foram realizadas com o intuito de tornar a formação mais detalhada como tempo de execução, formato da banca de avaliação e procedimentos de formalização nos documentos institucionais.

\section{Aspectos positivos e negativos da exigência do trabalho de conclusão de curso no curso de licenciatura em Geografia do IFRN}

Os participantes da pesquisa, ou seja, aqueles que responderam ao questionário, colaram grau entre os anos de 2006 e 2020.1. Foram contemplados diversos tipos de relatos sobre situações ao longo de 14 anos .

Quando os participantes foram indagados se apresentaram dificuldades na produção do Projeto de Pesquisa de TCC e quais foram as causas dos transtornos, cerca de 25 participantes declararam não terem tido nenhum tipo de problema. Destes, apenas um destacou que poderia ter tido um maior apoio do orientador.

Quanto aos outros participantes, 20 (vinte) pessoas afirmaram terem tido problemas para elaborá-lo. Destas, 02 (duas) apontaram deficiências de formação do próprio IFRN, inclusive em relação a pouca orientação na disciplina sobre a construção do projeto de pesquisa de TCC. Segundo esses participantes, essas deficiências interferiam na compreensão do método científico e na formulação de objetivos para o projeto de pesquisa de TCC. 
Além dessas dificuldades, 03 (três) participantes apontaram problemas financeiros e dependência de utilização dos computadores da instituição. Também outros 06 (seis) relataram não conseguirem conciliar o trabalho e a disciplina, e 07 (sete) participantes apontaram problemas de saúde envolvendo familiares, que acabaram afetando no desempenho.

A partir desse resultado, é importante destacar que fatores externos, como trabalho e problemas familiares são fatores decisivos na produção do projeto de pesquisa. Nesse sentido, estratégias devem ser elaboradas pelos docentes para garantir o máximo de suporte aos discentes para que tenham as mínimas condições de encaminhar um projeto de pesquisa com objetivos e metodologia definidos.

É importante destacar que, mesmo com essas condições mínimas, eventualmente, os problemas externos perduram vários meses, chegando a se estenderem por mais de 1 ano. Assim, podem ocorrer situações em que, mesmo com total dedicação dos professores, o concludente não consiga finalizar uma proposta de pesquisa. Provavelmente, uma conversa com esse aluno que se encontra imerso em tantos problemas pode ser uma atitude decisiva na permanência dele no curso, mesmo que ele precise pedir a prorrogação.

Um dos comentários destacados foi o de um(a) participante ao afirmar que "a licenciatura do IF é uma das poucas que se preocupa com o professor pesquisador. Aprender que fazer ciência é fundamental para o professor. Esse primeiro contato é sempre complicado".

De fato, há muita falta de clareza no momento de definição do projeto de pesquisa. Os estudantes que tiveram oportunidade de participar de atividades extracurriculares como Iniciação Científica e Atividades de Extensão, geralmente, encontram mais facilidade em recortar seus objetos de estudo, pois já se encontram discutindo referenciais teóricos e metodologias há algum tempo.

Todavia, aqueles estudantes trabalhadores que chegam nas aulas exaustos e sem a mínima condição de serem bolsistas ou mesmo voluntários ficam em grande desvantagem. Dessarte, privilegiar ou mesmo exaltar estudantes "completos" que sempre puderam se apropriar dos espaços da instituição de ensino superior não seria fruto de um pensamento elitista? Alunos com melhores condições financeiras e disponibilidade de tempo, se estivessem em outro contexto, teriam o mesmo desempenho? Como docentes, estaríamos dispostos a oportunizar momentos diferenciados, além dos horários que nos são delimitados no semestre, para orientar os estudantes com mais dificuldades de escrita acadêmica, aproveitando as ferramentas de comunicação virtual? 
Segundo Pinheiro Machado e Diniz (2020), as dificuldades da escrita acadêmica são normais na graduação e essa desarmonia pode perseguir o pesquisador por vários anos, se ele não buscar se atualizar e melhorar sua produção textual. Além disso, outra forma de melhorar a produção textual é a avaliação de textos por outros pesquisadores, atividade que é fundamental no processo de criação da proposta, por ser esse um momento de aparar as arestas e organizar as idéias para que o plano de trabalho fique mais claro

Quando foram questionados se se receberam alguma contribuição dos avaliadores do projeto de Pesquisa foram importantes para a melhoria do seu projeto, 44 (quarenta e quatro) participantes afirmaram terem recebido algum tipo de contribuição e 01 respondente afirmou não ter recebido contribuição.

Outro tópico investigado foi se a existência de um(a) docente responsável pelo acompanhamento da produção do Projeto de Pesquisa e do TCC contribuiu na finalização do seu TCC. Quanto a isso 43 (quarenta e três) participantes afirmaram que é importante a presença de um(a) docente no acompanhamento da produção do projeto de TCC, enquanto apenas 02 (duas) pessoas afirmaram não ser importante.

A partir das respostas dos participantes sobre a importância do docente responsável pelo acompanhamento da produção do Projeto de TCC é importante destacar que esse professor precisa estar atento às várias linhas de pesquisa que enriquecem as abordagens da ciência geográfica na dimensão espacial e no ensino de Geografia.

Uma das perguntas fundamentais do questionário foi a seguinte: "o processo de orientação do TCC foi satisfatório?". Sobre as respostas, 43 (quarenta e três) participantes afirmaram ter sido satisfatório e apenas 02 (dois) revelaram não ter sido satisfatório. Esses dois participantes tiveram experiências negativas quanto a esse processo, já que um(a) mudou de orientador faltando dois meses para a conclusão, e o(a) outro(a) se sentiu abandonado(a).

Já quanto à pergunta se o LIGIFRN cumpre seu papel na formação de professores de Geografia de acordo com a maioria dos entrevistados, o curso LIGIFRN cumpre sua função enquanto modalidade de ensino em uma Instituição de Ensino Superior, embora várias dificuldades estejam presentes.

Sobre essas dificuldades, na pergunta sobre as dificuldades na produção do TCC, dos respondentes, 17 (dezessete) pessoas afirmaram não terem tido problema algum e as outras 28 (vinte e oito) apontaram terem tido problemas. Dessas 28 pessoas, 07 (sete) indicaram dificuldades 
relacionadas ao trabalho, 02 (duas) apontaram a falta de recursos financeiros e de equipamentos, 06 (seis) relataram contratempos de saúde e adversidades na família, e 13 (treze) pessoas apontaram problemas relacionados, especificamente, ao corpo docente do curso. Sobre esses problemas do corpo docente, entre eles estão a falta de orientação, mudança de orientador, falta de clareza na definição dos objetivos e na aplicação da metodologia, e pouca orientação no sentido de perceber a inexperiência dos alunos na produção de um texto científico mais volumoso e na padronização das normas da ABNT. Todos esses problemas resultaram em dificuldades de escrita do TCC.

Assim como na fase de escrita do projeto, fatores externos ao IFRN determinam um bom desempenho do concludente. No entanto, aquilo que é de responsabilidade do IFRN deve ser avaliado.

A participação do(a) orientador(a) é fundamental na produção da pesquisa, pois ele(a), como pesquisador(a) mais experiente, influencia na forma do orientando se comportar. Zilbermann (2006) ressalta que o processo de orientação é uma aventura compartilhada. A autora priorizou essas discussões sobre a pós-graduação. No entanto, levando em consideração as devidas proporções, a redação do TCC exige dedicação e parceria de ambas as partes: ao orientando, cabe produzir os textos, e articular teoria, metodologia e resultados; e ao orientador, cabe colaborar e conduzir a produção do trabalho, indicando referências, sugerindo ajustes necessários e alertando para o cumprimento de prazos, com mudanças quando elas forem necessárias, afinal, todos nós temos problemas.

Além da parceria, o respeito à individualidade e a não realização de comparações são elementos fundamentais no processo formativo, devendo ocorrer de maneira substancial durante a fase de elaboração do TCC. São muitos os desafios que se impõem ao processo formativo, como problemas econômicos, problemas técnicos e éticos, além dos problemas nas relações interpessoais dentro das Instituições de Ensino Superior. Cabe ao corpo docente, articular proposições de melhorias em relação à produção do TCC naquilo que lhe é concernente.

Quanto à percepção dos participantes desta pesquisa sobre o papel que a produção do TCC exerceu em sua formação como professor(a), todos os participantes afirmaram que a feitura do TCC foi importante na construção da figura de docente pesquisador. Além disso, mesmo aqueles que se formaram e não exerceram à docência, afirmaram que se apropriaram dos conhecimentos construídos ao longo da elaboração do TCC e que eles contribuíram no exercício de outras profissões.

Algumas respostas se repetiram, e, por isso, foram agrupadas em 5 tipologias:

a) 03 participantes destacaram a oportunidade de realizar uma pesquisa que destaca características dos seus lugares de vivência; 
b) 09 participantes consideraram fundamental a produção do TCC, pois permitiu realizarem pesquisas sobre o ensino de Geografia;

c) 07 respondentes apontaram a contribuição do TCC em suas vidas na perspectiva da formação de professores-pesquisadores, entendendo que docência e pesquisa não se separam; d) 21 participantes destacaram o aprendizado na construção de um texto científico mais volumoso; e

e) 05 respondentes consideraram importante a elaboração do TCC, pois foi um momento de preparação para a pós-graduação.

Nesse sentido, percebe-se que educar pela pesquisa é uma importante estratégia para romper com o ensino tradicional (DEMO, 2000). Enquanto o texto é construído, orientador e orientando aprendem juntos. A autonomia do estudante é estimulada e os erros de escrita e de articulação entre teoria, metodologia e objetivos devem ser visualizados como etapas necessárias para a ampliação da capacidade cognitiva dos alunos.

Ao serem indagados se sentiam que estavam minimamente preparados para participar de seleções da pós-graduação, 36 entrevistados revelaram que se sentiam minimamente preparados para participarem de seleções e 9 participantes afirmaram não se sentirem preparados para concorrerem a uma vaga na pós-graduação.

Uma das respostas levanta questões importantes, por aconselhar os professores da LIGIFRN que "Se preparem melhor para condução da orientação com vistas a pós graduação. Apresentando novas possibilidades ao aluno e estimulando". Na mesma resposta, o(a) participante ainda relata sobre a sua própria experiência com sua orientadora e sobre as experiências de seus colegas que observava: "Praticamente só a minha orientadora fazia isso na época. Os demais professores só estimulavam o aluno a concluir, seja como fosse."

Antes de deter-se à resposta destacada, cabe questionar: é função do TCC preparar o graduando para a pós-graduação? Sim, a elaboração do TCC é uma etapa importante na preparação para a pós-graduação. No entanto, é importante salientar que, como bem mostraram as respostas ao questionário, nem todos os concludentes tem interesse em continuar na carreira acadêmica. É dever do(a) orientador(a) não autorizar a defesa até que o concludente esteja pronto para apresentar um TCC com a articulação satisfatória entre objetivos, metodologia e resultados. Nesse sentido, que haja liberdade para o graduando escolher qual caminho deve seguir. 
Em relação à resposta destacada anteriormente, estimular o aluno a concluir o curso, de acordo com as próprias condições, que envolvem a família, trabalho e situação financeira, é tarefa constante dos docentes. Contudo, essa tarefa não deve ser confundida com falta de responsabilidade do docente com a formação discente, estimulando o estudante a concluir "seja como fosse" a graduação

Prosseguindo com as respostas dos participantes, ao serem questionados se na época de produção do TCC perceberam se havia algum tipo de concorrência entre os colegas e se este ambiente competitivo chegou a atrapalhá-los, cerca de 33 pessoas afirmaram não terem percebido competição no contexto de elaboração do TCC e que havia geralmente um ambiente colaborativo. Diferentes desses, 12 participantes relataram perceber um ambiente competitivo, e destes, 09 afirmaram que a competição não chegou a atrapalhar, ao passo que os outros 03 confirmaram que a competição atrapalhou o desempenho. Entre os relatos registrados, destacam-se os dispostos a seguir, no Quadro 4:

QUADRO 4: RESPOSTAS DOS PARTICIPANTES SOBRE A COMPETITIVIDADE EM AMBIENTE ACADÊMICO

"Notei que havia competição sim. Principalmente com relação a banca. Os colegas falavam que se a banca não "humilhar" meu trabalho, então minha banca foi comprada"

"Sempre há. Quem faz mais rápido ou quanto está mais adiantado do outro, essas coisas." "Infelizmente as pessoas acabam criando competição onde não existe. Isso acaba nos afetando. É difícil produzir onde não há harmonia."

Fonte: Organizado a partir dos dados da pesquisa.

A competição no ambiente acadêmico é um fenômeno comum entre os docentes, principalmente, na pós-graduação. Dessa forma, os orientandos podem estar seguindo as práticas de competitividade de seus orientadores (SOUSA, 2013).

Diante disso, existem alunos que acabam reproduzindo um comportamento competitivo semelhante ao dos docentes. Quanto a esse comportamento competitivo, cabe destacar que ele é bastante impulsionado pela vaidade acadêmica, a qual, por sua vez, é um fenômeno muito comum em ambientes do ensino superior (PINHEIRO MACHADO, 2016). Bolsas de estudo, publicações e o sentimento de pertencimento a grupos fechados de pesquisa, em linhas gerais, são fatores que potencializam tais atitudes calcadas na disputa interminável e, geralmente, sem sentido. Essas disputas originam rótulos de sujeitos nas instituições de ensino superior, como "o(a) pesquisador(a)", "o(a) protegido(a)", o(a) que gosta de humilhar os colegas" e tantas outras tipologias nocivas. 
Segundo Nobre (2016, p.4):

como as crianças se espelham nos adultos, os alunos também se inspiram em nós, professores. Que tipo de alunos estamos ajudando a criar? Alguém que se importa com o outro ou que pretende subir os nefastos degraus acadêmicos a qualquer custo? Neuróticos solitários sem tempo e sem afeto? Pessoas sensíveis às dificuldades dos colegas ou pequenos sádicos que clamam por atenção em seus insignificantes círculos de vaidade?

Nesse sentido, professores orientadores podem ultrapassar as barreiras da relação acadêmica e aconselhar seus alunos a serem mais colaborativos. Segundo Cordula e Nascimento (2018), alguns problemas da educação brasileira são provocados pelos próprios docentes nas instituições de ensino, afetando não só as relações entre discentes, discentes e docentes, mas também entre os próprios docentes.

Um dos aspectos abordados anteriormente, no quadro 02, foi relacionado aos comentários da banca em relação ao trabalho e a nota atribuída. Segundo o relato do participante, há ruídos que afirmam haver "compra" da banca, mas sem haver detalhamento de evidências e como é feita essa barganha. Várias instituições adotam as tipologias aprovado e não aprovado para o resultado da avaliação do TCC. No entanto, no IFRN, em função da exigência do sistema de registro acadêmico, a banca precisa definir uma nota.

Segundo Luckesi (2014), as notas não refletem necessariamente a qualidade da aprendizagem, muito menos a capacidade do(a) concludente de melhorar sua maneira de fazer pesquisa e/ou ainda, sobretudo, de ser um bom professor ou uma boa professora. Uma nota é resultado de uma série de variáveis que escapam ao controle de quem a produziu.

A nota não leva em conta uma série de fatores que afetam a produção do TCC, entre eles estão: alunos que se dividem entre afazeres domésticos, trabalho e produção do TCC; que têm poucos recursos financeiros; que têm dificuldades de assimilação de teoria e método; dificuldades de delimitação do objeto de estudo na perspectiva de falta de um ambiente favorável à reflexão e à escrita, além de equipamentos; que têm estados emocionais abalados; e a quem falta e orientação do TCC. Parafraseando Luckesi (2014), o fetiche da nota da monografia se torna evidente em vários momentos. Torna-se, portanto, necessário combater a competição estéril que em nada contribui.

Outro ponto a ser destacado é o posicionamento da banca. O PPC da LIGIFRN (2018) prevê que a banca deve ser formada por professores especialistas. Existem bancas mais objetivas, formadas 
por membros compromissados que realmente analisaram o trabalho e que dedicaram atenção às contribuições, como indicação de referências e sugestões de recorte do objeto de estudo.

Contudo, infelizmente, em outras situações, é possível encontrar membros avaliadores que demonstraram falta de leitura do TCC; que se preocupam exageradamente com detalhes simples que podem ser resolvidos com revisão gramatical e de normas da ABNT; e que não conhecem muito bem os avanços nas diversas linhas de pesquisa, realizando uma interpretação baseada nos textos que leu somente na graduação, sem uma atualização fecunda. Além disso, ainda há, em muitos casos, uma situação mais grave: a que um membro da banca, para discordar do(a) professor(a) orientador(a), aparentemente revestido de preocupação com a melhoria do texto, faz um longo discurso de duras críticas ao trabalho, mas que não passa de verborragia acadêmica para honrar as discordâncias que surgem em reuniões e corredores das instituições.

A toxidez do ambiente acadêmico revela diferentes formas de agir por parte de professores e alunos. Alunos preocupados em demonstrar aos colegas que estão próximos de concluir o texto (ainda que isso não seja verdade), que se comparam constantemente aos colegas sem levar em consideração as individualidades, que tentam demonstrar que o tema ao qual estão debruçados é supostamente melhor, e ainda aqueles que se esforçam bastante para serem semelhantes aos seus orientadores (inclusive quando são arrogantes e competitivos). Todas essas atitudes contribuem para elevar a toxidez a um período que por si só já costuma a ser conturbado: o período final do curso.

Retornando às respostas ao questionário, quando foram solicitadas sugestões para os responsáveis pelo acompanhamento do TCC e para os orientadores, as palavras que mais apareceram foram "paciência”, “empatia", "carinho", "participação", "disponibilidade”, "humanidade” e, além disso, que orientadores deveriam exigir mais dos seus alunos. O conhecimento ou reconhecimento de saberes, na perspectiva de Demo (2000), é o resultado de um acúmulo de situações de aprendizagem. Dessa forma, se o orientando teve dificuldades no decorrer das disciplinas, é provável que possua muitos entraves no momento da escrita do TCC, por isso todas essas características citadas pelos participantes devem estar presente no corpo docente.

Tal contexto representa um convite à reflexão acerca do que ocorre durante o período da orientação de TCC. O concludente está realizando um esforço magistral para conciliar as demandas particulares com as obrigações do final do curso, como o Estágio Supervisionado, a comprovação das Atividades Teórico-Práticas de Aprofundamento (ATPA), a produção de TCC e as disciplinas do $8^{\circ}$ período. Quando se trata de um aluno trabalhador, a dificuldade em cumprir os prazos é ampliada em 
função do cansaço e distanciamento da instituição, tanto no aspecto físico (poucas disciplinas no final do curso e mais atividades externas), quanto pelo processo de construção do texto, que acaba se tornando um exercício mais autônomo (leia-se solitário) de leitura, reflexão e escrita.

Quanto aos orientadores, em função das características diversas de personalidade e de formação, situações variadas marcam a etapa de construção do TCC. Há orientadores que, de fato, não fazem revisão dos textos. Há aqueles que exigem muito dos orientandos a ponto de sufocá-los, pois implantam o "terror", sendo denominados de antiprofessores (PINHEIRO-MACHADO, 2016). Em contrapartida, há também, orientadores que cumprem minimamente suas funções realizando uma revisão sistemática do texto, indicando referências, tendo maior inclinação a escutar seus orientandos, e sendo capazes de aceitar que não dominam todos os temas e que possuem limitações, colocandose, dessa forma, em posição de aprendizado (HAGUETTE, 1994).

Para bons orientadores, o momento de construção do TCC é um exercício de aprendizagem. Seja em relação ao tem; ao ritmo de amadurecimento intelectual de um orientando em relação ao outro; e ao domínio de novas tecnologias, visto que já há alguns anos tornou-se comum não haver textos impressos, forçando muitos professores experientes a se acostumarem a analisar os textos na tela do computador (CHASSOT, 2006).

O Trabalho de Conclusão de Curso tem um papel primordial na construção do arquétipo docente pesquisador, o qual é um cientista que lida diariamente com situações que interferem no aprendizado dos estudantes e que tem condições de apresentar propostas de melhorias da vida em sociedade.

É preciso desmistificar o TCC como algo que somente bons alunos conseguem realizar, especialmente aqueles que desenvolveram trabalhos em laboratórios e grupos de pesquisa no decorrer da graduação ou que seja o clímax do processo formativo quando na realidade se trata de um componente curricular tão importante quanto os demais. Qualquer aluno minimamente empenhado em superar dificuldades e aceitar críticas para melhorias do trabalho pode apresentar um bom trabalho.

Vários alunos supervalorizam tanto o tema de TCC, que se esquecem de sua função na Educação Básica, que é a de abordar todos os conteúdos de maneira integrativa. Nesse sentido, não será possível a esse aluno discutir apenas o tema do seu TCC durante as aulas. Precisamos divulgar mais a importância de todos os conteúdos por meio de uma visão holística, integrativa. 
A preparação para a pós-graduação é um dos aspectos de direcionamento do TCC, pois um curso de graduação, independente da modalidade (licenciatura/bacharelado), deve fornecer as bases mínimas para verticalização da produção acadêmica por meio do ingresso na pós-graduação. No entanto, é importante destacar que alguns alunos simplesmente não têm interesse em participar de seleções.

O TCC de todos os alunos deve ser valorizado por mais que haja fragilidades. Isso porque, muitos não podem largar o trabalho para se dedicarem a pesquisas e dependerem de bolsas para sustentar a família. Nesse sentido, um aluno que trabalhou durante toda a graduação, chegando a adormecer em alguns momentos das aulas; que teve dificuldades para participar de trabalhos de campo; e que passou por diversas dificuldades financeiras e emocionais, ao conseguir produzir um TCC, ainda que este possua fragilidades (considerando que nenhum trabalho é perfeito e sempre pode haver melhorias), isso não deveria ser motivo de orgulho? De celebração? Evidentemente que sim!

Há elementos importantes a serem considerados, particularmente os relacionados à superação. Se houver atenção apenas aos alunos que apresentam bom desempenho ou possuem melhores condições financeiras, tal seletividade estaria coadunando com os objetivos do IFRN? Não estaríamos reforçando a meritocracia tão combatida nos discursos oficiais sobre a educação brasileira?

Outros problemas por vezes existentes como plágio, narcisismo intelectual, assédio moral e sexual são componentes que fragilizam o processo formativo e em nada contribuem para ele. Sobre um desses problemas, o plágio, Sanchez e Innarelli (2012, p.3 e 4) destacam que ele seria "o resultado de uma decisão individual, resultado de racionalização, uma decisão deliberada, construída com base em crenças pessoais e percepções de normas e de controle", ou seja, não há inocência nessa tomada de atitude, mas um movimento consciente e cercado de possibilidades de beneficiamento sem esforço. Logo, é o único problema cuja responsabilidade é apenas do aluno.

A partir das respostas dos entrevistados, ficou evidente, no curso de LIGIFRN, que os orientadores precisam refletir mais acerca do papel do TCC, sobre formas de mediação de conflitos e orientação para amenização dos entraves da escrita científica que existem pela falta de amadurecimento acadêmico que ainda é bastante incipiente na etapa de produção do primeiro TCC.

Antunes (1998) destaca que os elementos básicos dessa etapa da formação denominada orientação são: professores com mentalidade aberta para aceitarem essa missão; postura investigativa e estudiosa com a certeza de que não há limites para aprender; e desprendimento intelectual para 
aceitar a revisão de posturas, procedimentos e as próprias limitações. Antunes (1998), ao falar de inteligências múltiplas, destacou ainda que professores são agentes importantes, particularmente os que são críticos e reflexivos, pois acreditam que a formação ocorre de maneira "lenta, persistente e progressiva".

É necessário estimular os futuros professores a realizarem pesquisas em seus espaços de trabalho com aplicação de diferentes metodologias, investigação de temas de maior dificuldade e conhecimento de linhas de pesquisa diferentes dos habituais, pois, segundo Zeichner (1998), já na década de 1980, muitos professores da Educação Básica perceberam que as pesquisas conduzidas por acadêmicos não trazem contribuições significativas para melhorias na vida escolar. Nesse sentido, quem possui mais autoridade para discutir a Educação Básica? Professores que se debruçam sobre a situação do sistema educacional nas diversas esferas de ensino ou pesquisas de cunho acadêmico, não raramente, descoladas da realidade?

Partindo desse aspecto, devemos estimular mais a autoridade do argumento e não o argumento da autoridade (DEMO, 2000), pois os professores da Educação Básica possuem muita experiência e têm muita bagagem para argumentar sobre as dificuldades enfrentadas no Ensino Fundamental e Médio, ao contrário de muitos professores acadêmicos que estão distantes da realidade escolar e se revestem do cargo e, do status que vem com ele, para enunciarem soluções, não raramente, mágicas para resolução de problemas na educação.

Assim, os licenciandos, conscientes de sua capacidade intelectual para realização de pesquisas em seu fazer pedagógico, são capazes de promover mudanças que podem culminar em maior discernimento sobre seu papel como docentes, e disseminar metodologias ativas que colocam o aluno no centro da aula.

\section{CONSIDERAÇÕES FINAIS}

Apesar das várias dificuldades enfrentadas na Licenciatura em Geografia no IFRN, os participantes da pesquisa apontaram que o curso oferece uma boa formação, mas que algumas práticas precisam ser repensadas, em particular, quando se trata da fase de produção do TCC.

Muitos dos problemas apontados independem da instituição. Isso ficou evidente nesta pesquisa porque foi apontado que os fatores que interferem na produção gradual e tranquila do TCC 
são, em grande parte, de natureza exterior ao IFRN., mas que isso não parece estar claro para docentes e discentes.

A produção de um TCC é uma oportunidade de o licenciando se tornar um produtor de saberes e não apenas um divulgador de conhecimentos. Portanto, vale a pena continuar a estimular esse tipo de atividade. Nesse sentido, faz-se necessária a construção de um ambiente colaborativo e que seja desestimulada a competitividade. No entanto, isso ainda não parece estar claro para docentes e discentes.

\section{REFERÊNCIAS}

ANTUNES, C. As inteligências múltiplas e seus estímulos. 15ª ed. Campinas, SP: Papirus, 1998.

BATISTA, N.L.; DAVID, C.D; FELTRIN, T. Formação de professores de geografia no Brasil: considerações sobre políticas de formação docente e currículo escolar. Geografia Ensino e Pesquisa, Santa Maria, v. 23 e13, 2019. Disponível em: https://periodicos.ufsm.br/geografia/article/view/41062. Acesso em 20 de novembro de 2020.

CAVALCANTI, L.S.; SOUZA, V.C. A formação do professor de geografia para atuar na educação cidadã. Scripta Nova. Revista Electrónica de Geografía y Ciencias sociales, nº 494(08), 2014.

CAVALCANTI, L.S. O trabalho do professor de geografia e tensões entre demandas da $\begin{array}{llllllll}\text { formação e do cotidiano escolar. } 2017 & (35 \mathrm{~m} & 58 \mathrm{~s}) \text { Disponível } & \mathrm{em}\end{array}$ https://www.youtube.com/watch?v=3joNUB7uifY. Acesso em 08 de dezembro de 2020.

CHASSOT.A.I. Orientação virtual: uma nova realidade. In: BIANCHETTI, L.; NETTO MACHADO, A.M. A bússola do escrever: desafios e estratégias na orientação de teses e dissertações. $2^{\mathrm{a}}$ ed. Florianópolis: Ed. Da UFRSC; São Paulo: Cortez,2006.

CORDULA, E.B.L.; NASCIMENTO, G.C.C. Prática docente nas instituições de ensino superior: de novembro de vaidade intelectual à produção do saber. Revista Educação Pública, 2018.

DEMO, P. Educar pela pesquisa. Campinas: Autores Associados, 2000.

GUEDES, H.T.V.; GUEDES, J.C. Avaliação, pelos Estudantes, da Atividade "Trabalho de Conclusão de Curso" como Integralização do Eixo Curricular de Iniciação à Pesquisa Científica em um Curso de Medicina. Revista Brasileira de Educação Médica 36 (2): 162-171; 2012.

HUGUETTE, T. M. Universidade: nos bastidores da produção do conhecimento. Revista Brasileira de Estudos Pedagógicos. v. 75 n. 179-80-81 (1994).

IFRN. Projeto Político-Pedagógico do IFRN: uma construção coletiva. Instituto Federal de Educação, Ciência e Tecnologia do Rio Grande do Norte, 2012. Disponível em 
https://portal.ifrn.edu.br/ifrn/institucional/projeto-politico-pedagogico-1/lateral/menu-1/volume-1documento-base. Acesso em 05 de dezembro de 2020.

IFRN. Organização Didática do IFRN. Instituto Federal de Educação, Ciência e Tecnologia do Rio Grande do Norte, 2012. Disponível em https://portal.ifrn.edu.br/ifrn/institucional/projeto-politicopedagogico-1/lateral/menu-1/volume-3-organizacao-didatica. Acesso em 09 de dezembro de 2020.

IFRN. Projeto Pedagógico do Curso Superior de Licenciatura em Geografia presencial. Instituto Federal de Educação, Ciência e Tecnologia do Rio Grande do Norte, 2018. Disponível em https://portal.ifrn.edu.br/campus/natalcentral/cursos/cursos-de-graduacao/geografia.html. Acesso em 01 de dezembro de 2020.

LUCKESI, C.C. Sobre notas escolares distorções e possibilidades. São Paulo: Cortez, 2014.

MENEZES, V.S.; KAERCHER, N.A. A formação docente em geografia: por uma mudança de paradigma científico. Giramundo, Rio de Janeiro, V.2, N.4, 2015.

NOBRE, E. Soberba acadêmica, um pecado capital. Ponto Crítico, 24 jun. 2016. Disponível em: https://pontocritico.org/24/06/2016/soberba-academica-um-pecado-capital/. Acesso em: 16 maio 2018.

PINHEIRO-MACHADO, R. Precisamos falar sobre a vaidade na vida acadêmica. Carta Capital, São Paulo, 24 fev. 2016. Disponível em: https://www.cartacapital.com.br/sociedade/precisamosfalar-sobre-a-vaidade-na-vida-academica. Acesso em: 11 maio 2018.

PINHEIRO-MACHADO, R.; DINIZ, D. Curso de Escrita Acadêmica - Live de abertura com Debora Diniz. (2020) Disponível em https://www.youtube.com/watch?v=UAzzxvxuF9g (1h10m59s). Acesso em 15 de novembro de 2020.

SANCHEZ, O. P.; INANARELLI, P. B. Desonestidade acadêmica, plágio e ética. Revista da Fundação Getúlio Vargas, v.11, n. 1, p. 46-49, jan./jun. 2012.

SOUZA NETO, M.F. Aula de Geografia e algumas crônicas. Campina Grande: Bagagem, 2003.

VEIGA, I.P. Docência Universitária na Educação Superior. In: RISTOFF, D; SEVEGNANI, P. (Org.). Docência na Educação Superior. Brasília: Instituto Nacional de Estudos e Pesquisas Educacionais Anísio Teixeira, 2006. p. 87-98. V. 1.

ZEICHNER, K. M. Para além da divisão entre professor-pesquisador e pesquisador acadêmico In: GERALDI, C. M.; FIORENTINI, D.; PEREIRA, E. M. (orgs.) Cartografia do trabalho docente: professor(a)-pesquisador(a). Campinas, Mercado de Letras. ABL, 1998. pp. 207-236.

ZILBERMANN, R. Orientação: a aventura compartilhada. In: BIANCHETTI, L.; NETTO MACHADO, A.M. A bússola do escrever: desafios e estratégias na orientação de teses e dissertações. $2^{\mathrm{a}}$ ed. Florianópolis: Ed. Da UFRSC; São Paulo: Cortez, 2006. 